\title{
Artificial intelligence as an innovative approach for investment in the future of healthcare in Egypt
}

\author{
Eman Salman Taie* \\ Nursing Administration, Faculty of Nursing, Helwan University, Egypt
}

Received: March 23, 2020

Accepted: May 28, 2020

Online Published: June 22, 2020

DOI: $10.5430 / \mathrm{cns} . v 8 \mathrm{n} 3 \mathrm{p} 1$

URL: https://doi.org/10.5430/cns.v8n3p1

\begin{abstract}
Objective: To investigate perception of managers and patients about AI application in the healthcare domain in Egypt.

Methods: The study is quasi-experimental conducted in Shams Specialized Hospital, Dar el-Shefaa hospital in Cairo, and Dar El Foad Hospital. Study subjects were composed of two groups: managers (nurse and medical) and patients. Three questionnaires were used for data collection (Managers' knowledge about artificial intelligence, Managers' perception of artificial intelligence, and patients' perception about the application of AI in healthcare).

Results: All of the managers, either nurse or medical, had a lack of knowledge about AI. Nurse Managers perceived most items positively regarding the application of artificial intelligence in nursing, while medical managers perceived all items positively regarding the application of artificial intelligence in medicine. On the same line, the highest percentage of patients agreed upon the application of artificial intelligence in healthcare.

Conclusions: There was a highly significant difference $(p<.001)$ between managers' knowledge about AI before and after awareness sessions. The majority of nurses and medical managers' perceived the application of AI positively in nursing and medicine. Also, patients perceived the application of AI in healthcare positively.
\end{abstract}

Key Words: Artificial Intelligence, Healthcare, Nurse manager, Medical manager, Patients

\section{INTRODUCTION}

Artificial Intelligence (AI) is receiving a lot of attention from investors, the press, and the labor force across all industries. While AI has already achieved widespread adoption in specific sectors, the complexities of healthcare have resulted in slower adoption. ${ }^{[1,2]}$ Artificial Intelligence (AI) is becoming popular in many healthcare sectors. There is a paradigm shift to digitalize healthcare sectors to get a competitive advantage in the labor market. ${ }^{[3,4]}$ AI has managed to capture the attention of key healthcare stakeholders, who are now in a dilemma of whether or not to integrate it fully or partially in their businesses. ${ }^{[5,6]}$
The name behind the idea of AI is John McCarthy, who began research on the subject in 1955 and assumed that each aspect of learning and other domains of intelligence could be described so precisely that they can be simulated by a machine. ${ }^{[7-9]}$ Artificial Intelligence (AI), where computers perform tasks that used to require human intelligence, is currently being discussed in nearly every domain of science and engineering. AI is rapidly moving to change the healthcare system. There is no universally agreed upon definition of AI. The term broadly refers to computing technologies that resemble processes associated with human intelligence, such as reasoning, learning and adaptation, sensory understanding,

\footnotetext{
*Correspondence: Eman Salman Taie, Prof.; Email: Dr_emys@hotmail.com; Address: Nursing Administration. Faculty of Nursing, Helwan University, Egypt. 
and interaction..$^{[5,10]}$ The formal definition of AI would read as a field of science concerned with the computational understanding of what is commonly called intelligent behavior, and with the creation of intelligent agents that exhibit such behavior. Another definition stated that AI is the ability of machines to simulate human intelligence. Number it is the extension of human intelligence through the use of computers to do things humans used to do but in a more accurate way. ${ }^{[11,12]}$

AI technologies are being used or trialed for many purposes in the field of healthcare and research, including but not limited to the detection of disease, management of chronic conditions, delivery of health services, and drug discovery. ${ }^{[6,12,13]}$ AI technologies have the potential to help address important health care challenges. Still, they might be limited by the quality of available health data, and by the inability of AI to possess some human characteristics, such as compassion. ${ }^{[2,6]}$ Many countries, for example, China, have prioritized AI development by investing billions of dollars into AI industrial hubs. Other nations and global corporations have also invested in AI programming and the creation of innovative AI applications. Based on this trend, many organizations are nowadays increasingly focused their attention on investing in the healthcare industry by using $\mathrm{AI} \cdot{ }^{[4,14,15]} \mathrm{AI}$ is being used to improve efficiency in the delivery of healthcare by extending healthcare workforce capacities to counteract work labor shortages, minimize the cost, and maximize the quality of care. ${ }^{[1,7]}$

The hospital of the future will look quite different than the hospital of today. Rapidly emerging technologies and growing consumerism, along with demographic and economic changes, are expected to disrupt hospitals worldwide. The increasing number of inpatient healthcare services is being turned into home care and outpatient ambulatory services. Moreover, critically ill patients will continue to need acute care inpatient services. ${ }^{[9,14,16]}$ With the aging infrastructure in some countries and demand for more beds in others, hospital executives and governments should rethink how best to optimize inpatient and outpatient settings to connect with consumers, integrate digital technologies into traditional hospital services such as telenursing and telemedicine to truly create a health system without walls. ${ }^{[3,4]}$

\subsection{Significance of the study}

In a time of rapid healthcare transformation, health organizations must quickly adapt to evolving technologies, regulations, and consumer demands. AI offers the industry incredible potential to learn from past experiences and make better decisions for the future. AI can assist with proactive patient care, reduced future risk, and streamlined work processes. $^{[4,9]}$ The continued emphasis on cost, quality, and care outcomes will perpetuate the advancement of AI technology towards additional adoption and value across healthcare. The emerging use cases of Artificial Intelligence (AI) in the healthcare sector can be seen as a collection of technologies enabling machines to sense, comprehend, act and learn so they can perform administrative and clinical healthcare functions, as well as be used in research and for training purposes. Over the past several years, AI has multiplied productivity across a range of human endeavors, and its widespread adoption into everyday life is accelerating at a rapid pace. ${ }^{[2,9,15]}$

\subsection{Aim of the study}

The present study aims to investigate perception of managers and patients about AI application in the healthcare domain in Egypt through the following objectives:

(1) Assess managers' knowledge about artificial intelligence in the selected hospitals.

(2) Increase managers' awareness of artificial intelligence.

(3) Assess the application of artificial intelligence in healthcare as perceived by nurse managers and medical managers in the selected hospitals.

(4) Identify patients' perceptions of the application of artificial intelligence in the selected hospitals.

\subsection{Research hypotheses}

It was hypothesized that nurse and medical managers lack knowledge about artificial intelligence and that they will perceive AI negatively and patients too.

\section{SubJECTS AND Methods}

\subsection{Research design}

It is a quasi-experimental study.

\subsection{Study setting}

The study was conducted in one University hospital (Ain Shams Specialized Hospital, Therapeutic Institution in Cairo under the ministry of health $(\mathrm{MOH})$ Dar el-Shefaa hospital in Cairo, and (Dar El Foad Hospital) is a private hospital.

\subsection{Subjects}

The study subjects consisted of two groups:

\section{1st group: Managers}

All management levels of nurses and medical staff: top management, middle and functional management (1st line manager). All available managers with at least two years' experience were included in the study $(\mathrm{N}=165)$.

\section{2nd group: Patients}

The second group was comprised of (300) patients randomly selected from wards and critical care units in the selected hospitals. This sample included alert and oriented male and female patients with different diagnoses.

ISSN 2324-7940 E-ISSN 2324-7959 
Table 1. Distribution of study managers, according to hospitals $(\mathrm{N}=165)$

\begin{tabular}{|c|c|c|c|c|c|c|c|c|c|c|c|c|}
\hline \multirow{3}{*}{ Hospital } & \multicolumn{6}{|c|}{ Nurse Managers $(n=92)$} & \multicolumn{6}{|c|}{ Medical Managers $(n=73)$} \\
\hline & \multicolumn{2}{|c|}{ Top } & \multicolumn{2}{|c|}{ Middle } & \multicolumn{2}{|c|}{$\begin{array}{l}\text { First-line } \\
\text { Managers }\end{array}$} & \multicolumn{2}{|c|}{ Top } & \multicolumn{2}{|c|}{ Middle } & \multicolumn{2}{|c|}{$\begin{array}{l}\text { First-line } \\
\text { Managers }\end{array}$} \\
\hline & No. & $\%$ & No. & $\%$ & No. & $\%$ & No. & $\%$ & No. & $\%$ & No. & $\%$ \\
\hline \multicolumn{13}{|l|}{ University } \\
\hline $\begin{array}{l}\text { Ain Shams } \\
\text { Specialized Hospital }\end{array}$ & 1 & 1.0869 & 15 & 16.3 & 23 & 25 & 1 & 1.368 & 10 & 13.698 & 29 & 39.726 \\
\hline \multicolumn{13}{|c|}{ Therapeutic Institution under MOH } \\
\hline $\begin{array}{l}\text { Dar el-Shefaa hospital } \\
\text { in Cairo }\end{array}$ & 1 & 1.0869 & 9 & 9.78 & 13 & 14.13 & 1 & 1.368 & 8 & 10.9589 & 15 & 20.54 \\
\hline \multicolumn{13}{|l|}{ Private } \\
\hline Dar El Foad & 1 & 1.0869 & 7 & 7.6 & 12 & 13.04 & 1 & 1.368 & 3 & 4.1 & 5 & 6.84 \\
\hline
\end{tabular}

\subsection{Tools of data collection}

\subsubsection{Managers' knowledge about artificial intelligence questionnaire format}

This tool was developed by the researcher after reviewing the relevant literature. It was a self-administered questionnaire used to assess the selected managers' knowledge of artificial intelligence AI. It included questions such as the definition of artificial intelligence, its uses, opportunities and risks, segments, and kinds of $\mathrm{AI}$ in healthcare. Psychometric testing of the instrument for validity and reliability revealed a Cronbach Alpha coefficient of 0.88 for the study sample. The instrument had high construct validity (with a part-whole correlation of 0.90 ).

\subsubsection{Managers' perception of artificial intelligence ques- tionnaire}

This tool, also developed by the researcher, was a selfadministered questionnaire. It was used to assess nurse and medical managers' perception about the application of artificial intelligence in nursing and in medicine.

Managers' responses were measured on a 3 point Likert scale ranging from 1 - manager have disagreed, and 3 - manager have agreed. The perception was considered positive if the percent score was $60 \%$ or more and negative if the percent score was less than $60 \%$. Validity and reliability testing showed a Cronbach Alpha coefficient of the instrument at 0.85 for the study sample. The instrument had high construct validity (with a part-whole correlation of 0.91 ).

\subsubsection{Patients' perception of the application of artificial intelligence in the healthcare questionnaire}

This tool developed by the researcher after reviewing the relevant literature. It was a self-administered questionnaire used to assess patients' perceptions of the application of AI in healthcare.

Published by Sciedu Press

\subsection{Scoring system}

Patients' responses were measured on 3 point Likert scale ranging from 1 - patients has disagreed, and 3 - patients have agreed. The perceptions were considered positive if the percent score was $60 \%$ or more and negative if the percent score was less than $60 \%$. Validity and reliability testing showed a Cronbach Alpha coefficient of 0.89 for the study sample. The instrument had high construct validity (with a part-whole correlation of 0.90 ).

\subsection{Pilot study}

The aim of the pilot study was to test the practicability and to estimate the time required to complete tools. The researcher randomly selected ten managers from Ain Shams Specialized Hospital, seven from Dar el-Shefaa hospital in Cairo and five from Dar El Foad hospital, from different management levels. The time needed to fulfill 1 st and 2 nd questionnaire formats ranged between (15-20) minutes. The researcher randomly selected ten patients from each hospital. The time required to fulfill the third tool varied between (20-30) minutes. The Collection of pilot study data lasted for one month. All of these subjects were excluded from the primary study sample. Necessary modifications were done in the study tools according to pilot results.

\subsection{Field work}

The fieldwork of this study was executed over one year. Data collection began in mid-January 2018 and was completed on March 20, 2019. The researcher started to use the developed tools with the selected sample participants in their settings according to the available time for each of them after explaining the purpose of the study. The 1 st tool was to assess managers' knowledge about AI which lasted for two months. The first tool was pre/post test. Then, the awareness sessions were given to them five hours per day for two days; every awareness session was included (18-20) attendees to 
session for nurses and medical managers. Finally, both the 2nd , and 3rd questionnaires were lasted for four months to be completed.

\subsection{Administrative and ethical considerations}

To carry out the study in the predetermined hospitals, letters containing the aim of the study were directed from the researcher's faculty of nursing to hospitals' directors and also to nursing and medical directors to obtain their permission and help to conduct the study in their facility. The researcher then met the hospitals' nursing directors and medical directors and explained the purpose and methods of data collection for the study. The researcher also obtained the study subjects' approval orally after explaining the purpose and process of data collection for them. Confidentiality, anonymity, and the right to withdraw from the study at any time were guaranteed.

\subsection{Statistical analysis}

Data entry and analysis was completed using SPSS 13.0 statistical software package. Pearson correlation analysis was used for the assessment of the inter-relationships among quantitative variables. Statistical significance was considered at $p$-value $<.05$.

\section{RESULTS}

Table 2 displays managers' knowledge about AI before and after awareness sessions. It shows that all of them in the three of the studied hospitals were not aware of the complete definition of AI, its uses in nursing and medicine, its benefits, kinds, and segments, also opportunities and risks of AI in healthcare. Meanwhile, post awareness sessions, the highest percentage of them became completely aware of the mentioned items. There was a highly significant $(p<.001)$ difference between managers' knowledge about AI before and after awareness sessions.

Table 3 revealed Nurse managers' perception about the application of artificial intelligence in the healthcare. In all of the three studied hospitals more than half of them agreed upon all of the mentioned items except items 15th and 16th which were slightly less than half $(48.72 \%, 51.52 \%$ \& $53.85 \%$, $48.48 \%$ ) respectively in both of Ain Shams Specialized hospital and Dar el-Shefaa hospital, meanwhile it was high (90\%) in Dar El Foad hospital. Run on sentence There was a high significant $(p<.001)$ difference between nurse managers' perception about application of artificial intelligence in the three studied hospitals.

Table 4 illustrates medical managers' perceptions about the application of artificial intelligence in medicine. The highest percentage of them agreed upon all items in the table in all of the three hospitals. It seems that they have a positive perception of all of the items. There was significant $(p<.05)$ difference between the three of the studied hospitals.

Table 5 describes patients' perception about application of artificial intelligence in the healthcare. The highest percentage of them agreed upon most of the items in the table in the three studied hospitals. It seems that they have a positive perception of most of the items. There was no significant ( $p$ $<.05)$ difference between the three of the studied hospitals.

\section{Discussion}

Artificial Intelligence (AI) has extended its reach across the healthcare ecosystem, including drug development, diagnostics, care management, physician tools, and medication management. According to a report on healthcare system leaders, about $46 \%$ say AI is currently in use for clinical decision support, and $42 \%$ have or are planning to add AI for disease management. Most anticipate AI will impact the use of unstructured data at their health system within 3-5 years. However, the present study revealed that most of the study sample was not aware of the definition of AI. These findings were inconsistent with ${ }^{[7-9]}$ who emphasized that $\mathrm{AI}$ is a branch of computer science dealing with the simulation of intelligent behavior and the capability of a machine to imitate intelligent human behavior. This definition was supported by, ${ }^{[13,17]}$ who asserted that AI describes the work processes of machines that would require intelligence if performed by humans. The term 'artificial intelligence' thus means 'investigating intelligent problem-solving behavior and creating intelligent computer systems.' This definition also agreed by, ${ }^{[1,2]}$ who found that AI includes Natural Language Processing (NLP) and translation, pattern recognition, visual perception, and decision making.

Artificial Intelligence (AI) is playing a growing role in transformative changes in health and healthcare, both in and out of the clinical setting. AI is shaping the future of public health, community health, and healthcare delivery from a personal level to a system level. Regarding AI benefits, uses in nursing and medicine, the results of the present study revealed that the majority of the study sample was not aware of AI benefits and uses in healthcare either in nursing or medicine. These results were in contrast with ${ }^{[5,18,19]}$ who advocated that experts stress the role of AI in healthcare to supplement and enhance human judgment, not replace physicians and nurses. This finding was supported by Beam ${ }^{[20]}$ and 21 . Tyukin $^{[21]}$ who stated that AI is ready to assist physicians, customer service representatives, and administrative staff. Jiang ${ }^{[5]}$ and Hassanzadeh $^{[10]}$ also argue that AI could augment processes using automation, to reduce the nurses required to monitor patients, while filling gaps in healthcare labor shortages. It can also lower operational costs and make patient care more 
efficient. Also, the results of the present study were incon- judgment and diagnosis, AI-assisted robotic surgery, and sistent with the studies ${ }^{[6,14,16]}$ who asserted that AI would virtual nursing assistants.

be most beneficial in three other areas, physician's clinical

Table 2. Percentage distribution of managers' knowledge about artificial intelligence before and after awareness sessions

\begin{tabular}{|c|c|c|c|c|c|c|c|c|c|c|c|c|c|}
\hline \multirow{3}{*}{ Items } & \multicolumn{6}{|c|}{ Hospitals (Before awareness sessions) } & \multicolumn{6}{|c|}{ Hospitals (After awareness sessions) } & \multirow{3}{*}{$p$-value } \\
\hline & \multicolumn{2}{|c|}{$\begin{array}{l}\text { Ain Shams S H. } \\
\quad(n=79)\end{array}$} & \multicolumn{2}{|c|}{$\begin{array}{c}\text { Dar el-Shefaa } \\
(\mathbf{n}=\mathbf{5 7})\end{array}$} & \multicolumn{2}{|c|}{$\begin{array}{c}\text { Dar El Foad } \\
(n=29)\end{array}$} & \multicolumn{2}{|c|}{$\begin{array}{l}\text { Ain Shams S H. } \\
\qquad(\mathrm{n}=79)\end{array}$} & \multicolumn{2}{|c|}{$\begin{array}{c}\text { Dar el-Shefaa } \\
(\mathbf{n}=\mathbf{5 7})\end{array}$} & \multicolumn{2}{|c|}{$\begin{array}{c}\text { Dar El Foad } \\
(\mathbf{n}=29)\end{array}$} & \\
\hline & No. & $\%$ & No. & $\%$ & No. & $\%$ & No. & $\%$ & No. & $\%$ & No. & $\%$ & \\
\hline \multicolumn{14}{|c|}{ Definition of artificial intelligence } \\
\hline $\begin{array}{l}\text { Complete } \\
\text { definition }\end{array}$ & 0 & 0 & 0 & 0 & 0 & 0 & 74 & 93.67 & 48 & 84.2 & 27 & 93.1 & $<.001^{* *}$ \\
\hline $\begin{array}{l}\text { Incomplete } \\
\text { definition }\end{array}$ & 0 & 0 & 0 & 0 & 2 & 6.896 & 5 & 6.329 & 9 & 15.789 & 2 & 6.896 & $<.001^{* *}$ \\
\hline Do not Know & 79 & 100 & 57 & 100 & 27 & 93.1 & 0 & 100 & 0 & 100 & 0 & 100 & $<.001^{* *}$ \\
\hline \multicolumn{14}{|c|}{ Benefits of artificial intelligence in healthcare } \\
\hline Complete & 0 & 0 & 0 & 0 & 0 & 0 & 70 & 88.6 & 49 & 85.965 & 26 & 89.655 & $<.001^{* *}$ \\
\hline Incomplete & 2 & 2.53 & 2 & 3.5 & 4 & 13.79 & 5 & 6.329 & 7 & 12.28 & 2 & 6.896 & $<.001^{* *}$ \\
\hline Do not Know & 77 & 97.468 & 55 & 96.49 & 25 & 86.2 & 3 & 3.797 & 1 & 1.75 & 1 & 3.448 & $<.001^{* *}$ \\
\hline \multicolumn{14}{|c|}{ Uses of artificial intelligence in nursing } \\
\hline Complete & 0 & 0 & 0 & 0 & 0 & 0 & 72 & 91.139 & 54 & 94.736 & 25 & 86.2 & $<.001^{* *}$ \\
\hline Incomplete & 4 & 5.06 & 2 & 3.5 & 7 & 24.138 & 6 & 7.594 & 1 & 1.754 & 1 & 3.448 & $<.001^{* *}$ \\
\hline Do not Know & 75 & 94.936 & 55 & 96.49 & 22 & 75.86 & 1 & 1.265 & 2 & 3.5 & 1 & 3.448 & $<.001^{* *}$ \\
\hline \multicolumn{14}{|c|}{ Uses of artificial intelligence in medicine } \\
\hline Complete & 0 & 0 & 0 & 0 & 0 & 0 & 70 & 88.6 & 50 & 87.7 & 25 & 86.2 & $<.001^{* *}$ \\
\hline Incomplete & 2 & 2.53 & 3 & 5.263 & 5 & 17.24 & 5 & 6.329 & 5 & 8.77 & 2 & 6.896 & $<.001^{* *}$ \\
\hline Do not Know & 77 & 97.468 & 54 & 94.736 & 24 & 82.758 & 3 & 3.797 & 2 & 3.5 & 0 & 100 & $<.001^{* *}$ \\
\hline \multicolumn{14}{|c|}{ Kinds of artificial intelligence } \\
\hline Complete & 0 & 0 & 0 & 0 & 0 & 0 & 74 & 93.67 & 49 & 85.965 & 24 & 82.758 & $<.001^{* *}$ \\
\hline Incomplete & 0 & 0 & 0 & 0 & 0 & 0 & 4 & 5.063 & 7 & 12.28 & 3 & 10.344 & $<.001^{* *}$ \\
\hline Do not Know & 79 & 100 & 57 & 100 & 29 & 100 & 1 & 1.265 & 1 & 1.75 & 2 & 6.896 & $<.001^{* *}$ \\
\hline \multicolumn{14}{|c|}{ Segments of artificial intelligence in healthcare } \\
\hline Complete & 0 & 0 & 0 & 0 & 0 & 0 & 72 & 91.139 & 50 & 87.7 & 25 & 86.2 & $<.001^{* *}$ \\
\hline Incomplete & 0 & 0 & 0 & 0 & 0 & 0 & 4 & 5.063 & 5 & 8.77 & 2 & 6.896 & $<.001^{* *}$ \\
\hline Do not Know & 79 & 100 & 57 & 100 & 29 & 100 & 3 & 3.797 & 2 & 3.5 & 0 & 100 & $<.001^{* *}$ \\
\hline \multicolumn{14}{|c|}{ Opportunities for artificial intelligence in healthcare } \\
\hline Complete & 0 & 0 & 0 & 0 & 0 & 0 & 75 & 94.936 & 47 & 82.456 & 26 & 89.655 & $<.001^{* *}$ \\
\hline Incomplete & 2 & 2.53 & 2 & 3.5 & 3 & 10.344 & 4 & 5.063 & 9 & 15.789 & 2 & 6.896 & $<.001^{* *}$ \\
\hline Do not Know & 77 & 97.468 & 55 & 96.49 & 26 & 89.655 & 0 & 100 & 1 & 1.75 & 1 & 3.448 & $<.001^{* *}$ \\
\hline \multicolumn{14}{|c|}{ Risks of artificial intelligence in healthcare } \\
\hline Complete & 0 & 0 & 0 & 0 & 0 & 0 & 76 & 96.2 & 51 & 89.47 & 28 & 96.55 & $<.001^{* *}$ \\
\hline Incomplete & 2 & 2.53 & 3 & 5.263 & 5 & 17.24 & 3 & 3.797 & 5 & 8.77 & 1 & 3.448 & $<.001^{* *}$ \\
\hline Do not Know & 77 & 97.468 & 54 & 94.736 & 24 & 82.758 & 0 & 100 & 1 & 1.75 & 0 & 100 & $<.001^{* *}$ \\
\hline
\end{tabular}

The healthcare industry is made up of several segments. Through a review of companies developing AI solutions for health, health practitioners using AI, and researchers looking into the potential of $\mathrm{AI}$ and health, it was found that AI is employed in a variety of ways across the different segments. Regarding segments of AI in healthcare, the results of the present study revealed that the entire study sample was not aware of those segments. There was inconsistency with Al-shamasneh ${ }^{[3]}$ and Erguzel ${ }^{[4]}$ who stated that hospitals, either governmental or private healthcare centers and nursing homes are considered segments for AI use in healthcare. For example, in oncology AI can be used to aid doctors in the diagnosis and treatment of seven types of cancer. Also, AI is used to analyze data and research evidence and to improve the quality of the report, in turn, increasing patient trust. Imison ${ }^{[11]}$ and Salman ${ }^{[12]}$ added that pharmaceuticals are another segment for AI, which includes manufacturing, extraction, processing, purification, and packaging of chemical materials for use as medications for humans or animals. This situation was supported by Erguzel ${ }^{[4]}$ and Sensmeier ${ }^{[22]}$ who asserted that medical equipment and supplies are an AI segment, including establishments primarily manufacturing medical equipment and supplies, e.g., surgical, dental, orthopedic, ophthalmologic, and laboratory instruments. 
Table 3. Percentage distribution of nurse managers' perception about the application of artificial intelligence in nursing (N $=92)$

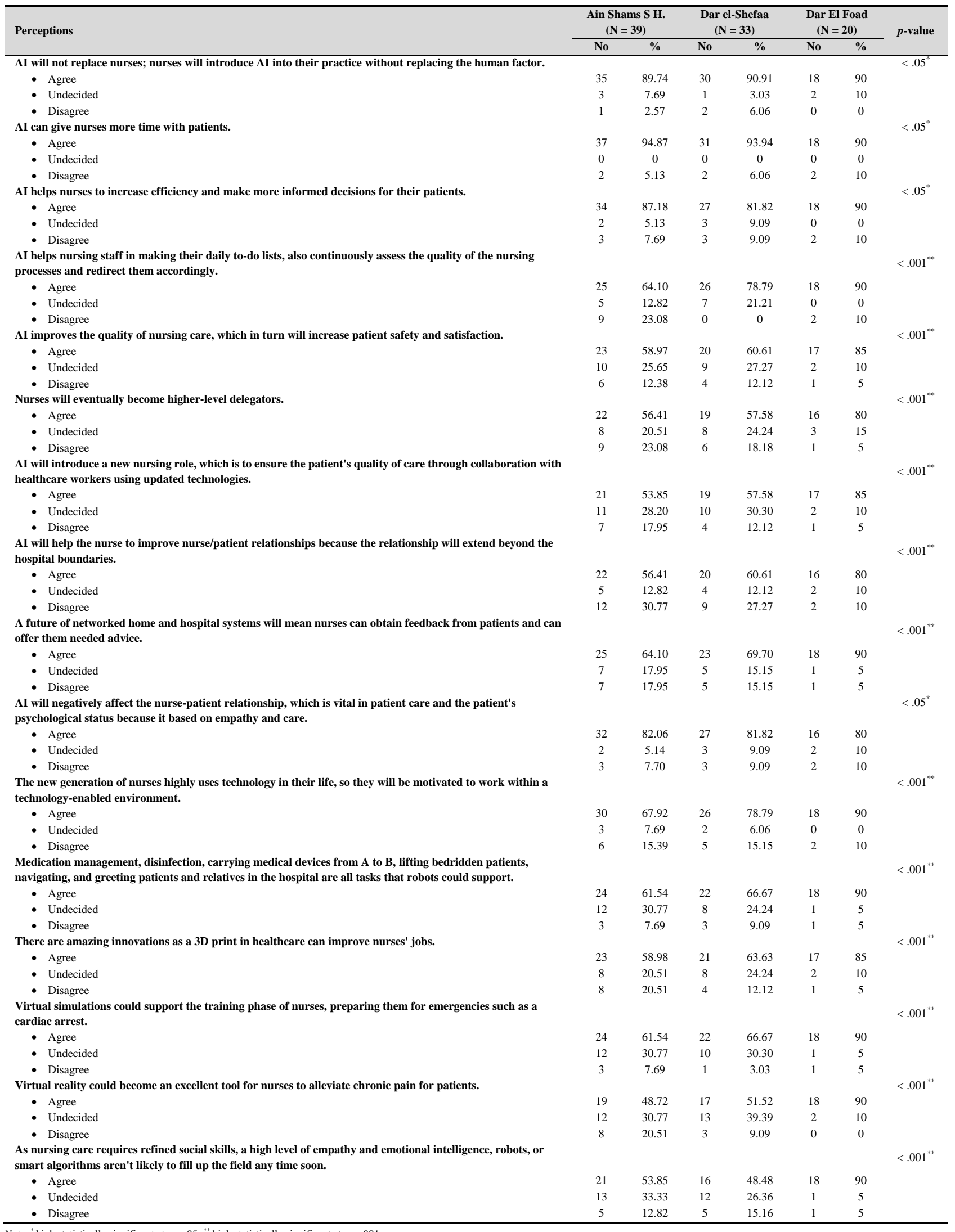

Note. " high statistically significant at $p<.05 ;{ }^{* *}$ high statistically significant at $p<.001$ 
Table 4. Percentage distribution of medical managers' perception about the application of artificial intelligence in the medicine $(\mathrm{N}=73)$

\begin{tabular}{|c|c|c|c|c|c|c|c|}
\hline \multirow[t]{2}{*}{ Perceptions } & \multicolumn{2}{|c|}{$\begin{array}{l}\text { Ain Shams S H. } \\
(\mathrm{N}=40)\end{array}$} & \multicolumn{2}{|c|}{$\begin{array}{c}\text { Dar el-Shefaa } \\
(\mathbf{N}=\mathbf{2 4})\end{array}$} & \multicolumn{2}{|c|}{$\begin{array}{l}\text { Dar El Foad } \\
(\mathbf{N}=9)\end{array}$} & \multirow[t]{2}{*}{$p$-value } \\
\hline & No & $\%$ & No & $\%$ & No & $\%$ & \\
\hline $\begin{array}{l}\text { It will be difficult to totally replace doctors' consultation with digital tools because digitals cannot } \\
\text { imitate doctors' nonverbal communication. }\end{array}$ & & & & & & & $<.05^{*}$ \\
\hline - Agree & 35 & 87.50 & 20 & 83.33 & 9 & 100 & \\
\hline - Undecided & 4 & 10.00 & 2 & 8.33 & 0 & 0 & \\
\hline - Disagree & 1 & 2.50 & 2 & 8.33 & 0 & 0 & \\
\hline Doctor's judgment is a vital part of clinical activity and the essence of being a doctor. & & & & & & & $<.05^{*}$ \\
\hline - Agree & 37 & 92.50 & 22 & 91.67 & 9 & 100 & \\
\hline - Undecided & 3 & 7.50 & 2 & 8.33 & 0 & 0 & \\
\hline - Disagree & 0 & 0 & 0 & 0 & 0 & 0 & \\
\hline $\begin{array}{l}\text { Lay people are unfamiliar with medical terminology, which in turn can face them to risk of } \\
\text { misunderstanding and estimate how much the situation is critical. }\end{array}$ & & & & & & & $<.05^{*}$ \\
\hline - Agree & 37 & 92.50 & 23 & 95.83 & 8 & 88.88 & \\
\hline - Undecided & 2 & 5.00 & 1 & 4.17 & 1 & 11.12 & \\
\hline - Disagree & 1 & 2.50 & 0 & 0 & 0 & 0 & \\
\hline AI reduces the trust and quality of the doctor/patient relationship. & & & & & & & $<.05^{*}$ \\
\hline - Agree & 33 & 82.50 & 20 & 83.33 & 9 & 100 & \\
\hline $\begin{array}{l}\text { If there is a contrast between doctors and AI opinion, which will be considered as 'right'? This can be } \\
\text { differing by generations and individuals. }\end{array}$ & & & & & & & $<.05^{*}$ \\
\hline - Agree & 30 & 77.50 & 19 & 79.17 & 9 & 100 & \\
\hline - Undecided & 7 & 7.50 & 4 & 16.66 & 0 & 0 & \\
\hline - Disagree & 3 & 17.50 & 1 & 4.17 & 0 & 0 & \\
\hline $\begin{array}{l}\text { Cannot definitely identify responsible for causing harm caused by AI mistakes may include the } \\
\text { computer programmer or the clinician and others. }\end{array}$ & & & & & & & $<.05^{*}$ \\
\hline - Agree & 37 & 92.50 & 22 & 91.66 & 9 & 100 & \\
\hline - Undecided & 2 & 5.00 & 1 & 4.17 & 0 & 0 & \\
\hline - Disagree & 1 & 2.50 & 1 & 4.17 & 0 & 0 & \\
\hline $\begin{array}{l}\text { AI will decrease doctors/patients face-to-face contact, which will reduce health promotion } \\
\text { interventions. }\end{array}$ & & & & & & & $<.05^{*}$ \\
\hline - Agree & 38 & 95 & 23 & 95.83 & 9 & 100 & \\
\hline - Undecided & 1 & 2.5 & 0 & 0.00 & 0 & 0 & \\
\hline - Disagree & 1 & 2.5 & 1 & 4.17 & 0 & 0 & \\
\hline AI can use high-fidelity simulations and developing clinical scenarios to enhance doctors' training. & & & & & & & $<.05^{*}$ \\
\hline - Agree & 36 & 90 & 22 & 91.66 & 9 & 100 & \\
\hline - Undecided & 2 & 5 & 1 & 4.17 & 0 & 0 & \\
\hline - Agree & 38 & 95 & 21 & 87.50 & 9 & 100 & \\
\hline - Undecided & 0 & 0 & 0 & 0.00 & 0 & 0 & \\
\hline - Disagree & 2 & 5 & 3 & 12.50 & 0 & 0 & \\
\hline AI helps to reduce human diagnostic and therapeutic errors. & & & & & & & $<.05^{*}$ \\
\hline - Agree & 38 & 95 & 23 & 95.83 & 9 & 100 & \\
\hline - Undecided & 1 & 2.5 & 1 & 4.17 & 0 & 0 & \\
\hline - Disagree & 1 & 2.5 & 0 & 0.00 & 0 & 0 & \\
\hline $\begin{array}{l}\text { AI helps doctors in medical imaging, pathology, dermatology, genetics and genomics, oncology, } \\
\text { neurology, eye care, diabetes care, and critical care. }\end{array}$ & & & & & & & $<.05^{*}$ \\
\hline - Agree & 39 & 97.5 & 24 & 100 & 9 & 100 & \\
\hline - Undecided & 0 & 0 & 0 & 0 & 0 & 0 & \\
\hline - Disagree & 1 & 2.5 & 0 & 0 & 0 & 0 & \\
\hline
\end{tabular}

Note. "high statistically significant at $p<.05$

New AI technologies can help to move closer towards achieving 'precision medicine,' which is an emerging approach to disease treatment and prevention that considers individual variability in genes, environment, and lifestyle. From the present study results, the majority of the study sample was not aware of AI opportunities and risks in healthcare. This finding was contradicted with the studies ${ }^{[1,16,23]}$ that AI could identify signs of disease in medical images faster and more accurately than humans. This finding agreed with those $\mathrm{e}^{[5,6]}$ who added that $\mathrm{AI}$ is impactful in clinical decision-making, in particular disease diagnosis; because AI can analyze and report on large volumes of data, across different modalities, to detect disease and guide clinical decisions.
On the other hand, regarding the risks of AI in healthcare, both accuracy and security are required to foster trust in these new AI technologies. The researchers ${ }^{[15,18]}$ stated that the lack of confidence in AI systems might significantly affect the adoption of AI technologies that may otherwise offer significant improvements in patient outcomes. Also, $\mathrm{Bach}^{[2]}$ and Mohammadzadeh ${ }^{[13]}$ added that trust in AI technologies could be gained through greater transparency in how results are achieved. The studies ${ }^{[1,3,8,9]}$ also advocated that the accuracy, reliability, security, and clinical use of medical AI technologies would need to be ensured through a combination of standards and regulation. 
Table 5. Percentage distribution of patients' perception about the application of artificial intelligence in healthcare $(\mathrm{N}=$ 300)

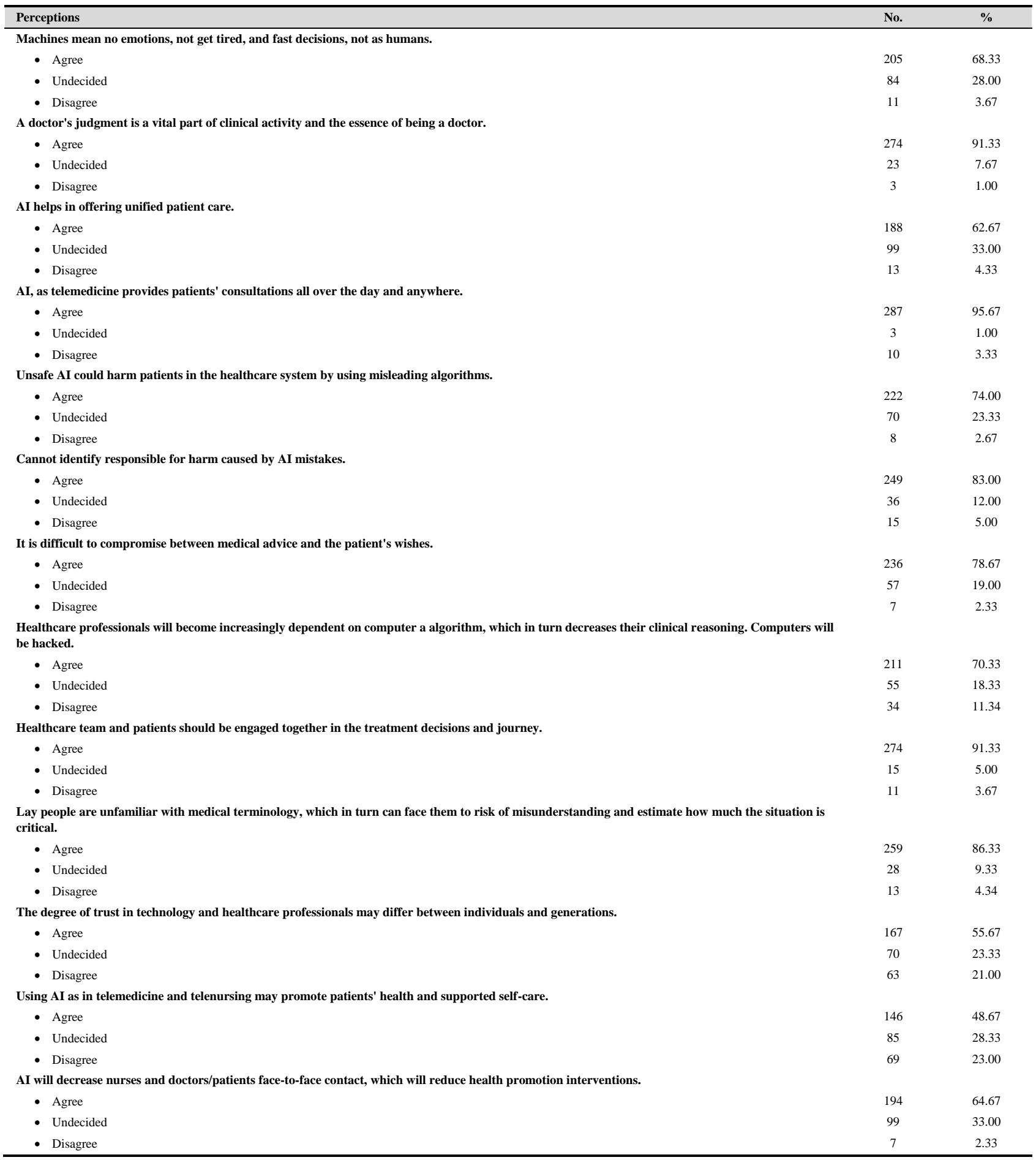

Being a nurse is a highly demanding, but genuinely fulfill- the burden of many monotonous and repetitive tasks. Coning job with the chance to touch many people's lives as it cerning nurse managers' perception of the application of requires the core of what makes us human. i.e., paying atten- AI in nursing in the present study, most of them perceived tion, being empathetic and caring. It will never be replaced $\mathrm{AI}$ in nursing positively. This finding was consistent with by technology. However, innovations can relieve nurses of those ${ }^{[2,5,7]}$ who stated that AI would help nursing staff not 
only receive digital to-do lists but can also see the current status and quality of the nursing processes at all times allowing them to react to them at an early stage. This finding was also supported by those ${ }^{[9,14,16]}$ who asserted that AI technology would fundamentally change nursing over the coming years and, provided it is used correctly, it seems it really could improve the quality of care and lead to increased patient safety.

Furthermore, The researchers ${ }^{[1,6]}$ concluded that intruding AI into nursing practice would not replace the human factor; only nursing can provide hands-on patient care. $\mathrm{Bach}^{[2]}$ and Buch $^{[6]}$ emphasized that more nurse involvement in technological development will benefit nurses because they will become higher-level delegators. This finding was similar to those ${ }^{[5,6]}$ who found that the field of nursing care can reap the fruits of the technology, through using virtual simulations to support nurses' training and preparing them for emergencies such as a cardiac arrest. This finding was in contrast with those $\mathrm{e}^{[6,14,16]}$ who proposed that nursing care requires refined social skills, high level of empathy and emotional intelligence, for which robots or smart algorithms are not likely to fill up the field any time soon. The technology should be evaluated for its ability to promote quality of care, improve clinician work satisfaction, and lower costs. From the researcher's point of view, AI will never replace nurses, but it will improve the quality of care and patient safety.

Artificial Intelligence (AI) has the potential to improve patient care and the delivery of health services across a broad range of clinical specialties. Some specialties have incorporated AI for some time. In other cases, AI tools are just emerging or are in earlier stages. The result of the present study revealed that medical managers had a positive perception of the application of AI in medicine. This situation was agreed to by those ${ }^{[15,18]}$ who stated that radiology, pathology, and dermatology are anticipated to be the first clinical specialties to experience large-scale change due to the incorporation of AI into work practices. This situation was supported by those $\mathrm{e}^{[4,22]}$ who asserted that the current focus of AI in medical imaging is on assisting imaging professionals in the reading and interpretation of images. He added that AI could make predictions when interpreting images at a level of competence comparable to that of a physician. These findings were consistent with those ${ }^{[3,4]}$ who mentioned that robotic-guidance becomes more prevalent in spine surgery and technology's accuracy, reduction of intraoperative radiation, and surgical efficiency. On the same line, Bach $^{[2]}$ and Buch $^{[6]}$ advocated for the use of AI in pathology which may also be linked to the fact that digital pathology creates large volumes of data that can be used in algorithms to recognize predictive patterns.
Meanwhile, Jiang ${ }^{[5]}$ and Buch ${ }^{[6]}$ were in contrast with the previous and stated that the nature of the relationship between physicians and their patients has evolved. Doctors and patient relationships will be affected. Applications of AI could range from a doctor-facing decision support tool, potentially unnoticed by the patient, to an autonomous AI system accessible from the patient's own devices; diagnosing and treating conditions without human clinical involvement. This situation was supported by those ${ }^{[4,11]}$ who emphasized that reduced face-to-face contact could reduce opportunities for doctors to offer health promotion interventions. From the researcher's point of view, personalized medicine today is kind of a utopian buzz term: a health care approach where diagnoses and treatments are highly tailored to meet the patient's personal and family history as well as his or her specific risk factors and genetics. At the moment, many personalized medicine options are little more than fads, but AI can change that. As more and more data is collected and analyzed by deep learning models, personalized medicine may well become a commonplace.

Gaining that trust will be one of the essential steps to the development of AI in healthcare. For this reason, developers should continue to focus on the utility of AI to the patient rather than seek explicit approval from the outset. Patients in this study perceived AI positively. This situation was consistent with those ${ }^{[6,12,13]}$ who stated that there is greater acceptance of or reliance on AI among younger users. This finding was in ${ }^{[4,14,16]}$ who mentioned that responsibility and liability for misdiagnosis or treatment and its impact on care decisions is a topic of debate. The studies ${ }^{[5,6,16]}$ added that transparency of decisions might be vital to empowering patients and gaining trust so that AI will affect patients' empowerment negatively. From the researcher's point of view, not all parts of the population will benefit equally from AI systems because there is limited data about populations, such as people living with rare diseases and others who are not present in the country's database.

\section{Conclusions}

There was a highly significant difference $(p<.001)$ between managers' knowledge about AI before and after awareness sessions conducted by the researcher. The majority of nurse and medical managers' perceived application of AI positively in nursing and medicine. Also, patients viewed the application of AI in healthcare positively.

\section{RECOMMENDATIONS}

Based on the study findings, the following recommendations were suggested: 
- Restructuring of nursing and medical curricula to introduce the AI concept in healthcare.

- Development and adoption of new staffing and training strategies to use technology in healthcare.

- Utilization of high-performing and reliable network capabilities to fit using AI.

- Provision of access to high-quality, unbiased data sets critical to the success of $\mathrm{AI}$ in healthcare.

- Preparation of ethical standards to safeguard the patient's information.

- Find a balance between the costs of the application of $\mathrm{AI}$ in healthcare and its potential benefits.

- Identification and sharing of best practices, and foundational principles for AI policy, regulation in healthcare in Egypt.

- Creation of a mechanism to support the adoption of best practice AI regulation and policy within healthcare settings in Egypt.

- Reengineering of some of the Egyptian hospitals in different sectors to use AI.

- Establish a research focus on AI in healthcare in Egypt in different settings and to provide more rigorous results.

- Strengthen a prescriptive theory about AI in healthcare in the search for gaining sustainable competitive advantage for Egyptian hospitals.

\section{CONFLicts OF InTEREST Disclosure}

The authors declare they have no conflicts of interest.

\section{REFERENCES}

[1] Cowie J. Evaluation of a Digital Consultation and Self-Care Advice Tool in J Environ Res Public Health. 2018; 15: E896. PMid: 29724040. https://doi .org/10.3390/ijerph15050896

[2] Tran BX, Vu GT, Ha GH, et al. Global Evolution of Research in Artificial Intelligence in Health and Medicine: A Bibliometric Study. Journal of Clinical Medicine. 2019; 8: 360. PMid: 30875745. https://doi.org/10.3390/jcm8030360

[3] Al-shamasneh ARMS. Artificial Intelligence Techniques for Cancer Detection and Scientific Journal. 2017; 13: 342-70. https: //doi.org/10.19044/esj.2017.v13n3p342

[4] Erguzel T, Ozekes S. Artificial intelligence approaches in psychiatric disorders. The Journal of Neurobehavioral Studies. 2019; 1: 52-53. https://doi.org/10.5455/JNBS. 1405259279

[5] Jiang F, Jiang Y, Zhi H, et al. Artificial intelligence in healthcare: past, present, and future. Stroke Vasc Neurol. 2017; 2: 230-243. http s://doi .org/10.1136/svn-2017-000101 PMid:29507784 PMCid:PMC5829945

[6] Buch V, Varghese G, Maruthappu M. Commentary Artificial intelligence in diabetes care. Diabet Med. 2018; 35: 495-7. PMid: 29368355. https://doi.org/10.1111/dme.13587

[7] Shulman C. How Hard is Artificial Intelligence? Evolutionary Arguments and Selection Effects. Journals of Consciousness Studies. 2012; 19: 1-23.

[8] Fogel AL, Kvedar JC. Artificial intelligence powers digital medicine. NPJ Digit Med. 2018; 1: 5. PMid: 31304291. https://doi .org/ 10.1038/s41746-017-0012-2

[9] Commins J. United Healthcare, AMA push new ICS-10 codes for social determinates of health. Health Leaders. 2019. Avaible from: https://www.healthleadersmedia.com/clinical-care/ unitedhealthcare-ama-pushnew-icd-10-codes-social-d eterminants-health

[10] Hassanzadeh H, Nguyen A, Karimi S, et al. Transferability of artificial neural networks for clinical document classification across hospitals: A case study on abnormality detection from radiology reports. J Biomed Inform. 2018. PMid: 30026067. https: //doi.org/10.1016/j.jbi.2018.07.017
[11] Imison C, Castle-Clarke S, Watson R, et al. Delivering the benefits of digital health care. The Nuffield Trust. 2016; 1-108.

[12] Salman M, Ahmed AW, Khan A, et al. Artificial Intelligence in Bio-Medical Domain An Overview of AI-Based Innovations in Medical. Int J Adv Comput Sci Appl. 2017; 8: 319-27. https: //doi.org/10.14569/IJACSA.2017.080842

[13] Mohammadzadeh N, Safdari R. Artificial Intelligence Tools in Health Information Management. International Journal of Hospital Research. 2012; 1: 71-6.

[14] Gawad J, Bonde C. Artificial Intelligence: Future of Medicine and healthcare. Biochemistry: An Indian Journal. 2017; 11(2): 113.

[15] Graham S, Depp C, Lee EE, et al. Artificial Intelligence for Mental Health and Mental Illnesses: an Overview. Curr. Psychiatry Rep. 2019; 21(11): 11. PMid: 31701320. https://doi.org/10.1007/ s11920-019-1094-0

[16] Prabu AJ, Narmadha J, Jeyaprakash K. Artificial Intelligence Robotically Assisted Brain Surgery. IOSR Journal of Engineering. 2014; 4 : 9-14. https://doi .org/10.9790/3021-04540914

[17] Derrington D. Artificial Intelligence for Health and Health Care. Health it. 2017; 7508: 65.

[18] Siau K, Wang W. Building Trust in Artificial Intelligence, Machine Learning, and Robotics. Cutter Business Technology Journal. 2018; 31(2): 47-53

[19] Siau K. Education in the Age of Artificial Intelligence: How will Technology Shape Learning? The Global Analyst. 2018; (73): 22-24.

[20] Beam AL, Kohane IS. Translating artificial intelligence into clinical care. J Am Med Assoc. 2016; 316(22): 2368-2369. PMid: 27898974. https://doi.org/10.1001/jama.2016.17217

[21] Tyukin IY, Gorban AN, Sofeykov KI, et al Knowledge transfer between artificial intelligence systems. Front Neurorobot. 2018; 12 : 49. PMid: 30150929. https://doi.org/10.3389/fnbot. 2018 .00049

[22] Sensmeier J. Harnessing the Power of Artificial Intelligence. Nursing Management. 2017; 48: 14-19. PMid: 29023284. https: //doi.org/10.1097/01. NUMA.0000526062.69220.41

[23] Latonero M. Governing artificial intelligence: Upholding human rights \& dignity. Data \& Society. 2018. 